\title{
Applications Invited
}

for

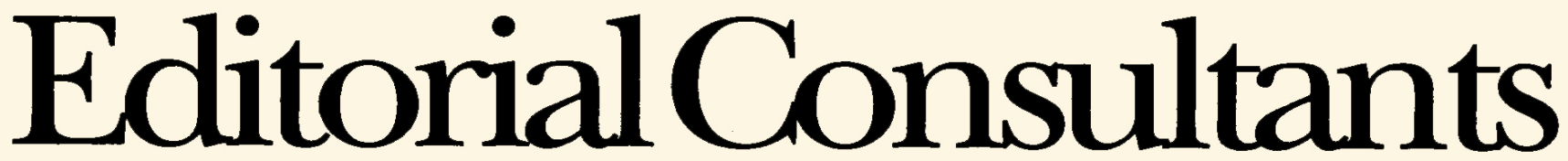

The JCPDS - International Centre for Diffraction Data, is inviting applications for Editorial Consultants. Editorial Consultants play a vital role in the evaluation of experimental and calculated X-ray powder diffraction data before such data is added to the Powder Diffraction File. The system of editorial consultants has been in place for more than thirty years and the International Centre has been fortunate in the availability of experienced professionals who are able to work on a part time basis in this area.

Because of the expanded work load over the past several years, due to the processing of increasing numbers of patterns and the improvement in quality of data, the Board of Directors of the International Centre has decided to supplement the existing slate of Editorial Consultants. The new positions will be paid-for-services on a finite-term, renewable contract basis.

Anyone interested in learning more about these positions should write to

Mr. Julian Messick, General Manager

JCPDS-ICDD

1601 Park Lane

Swarthmore, PA 19081-2389 U.S.A.

and enclose a detailed summary of professional experience.

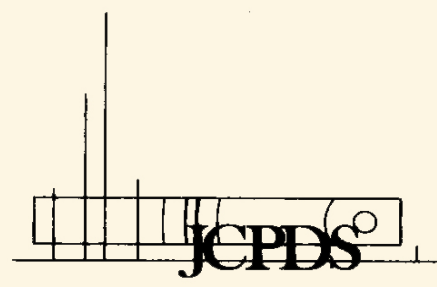




\section{From now onallother powder iflifractometers will hemeasured againsthis one.}

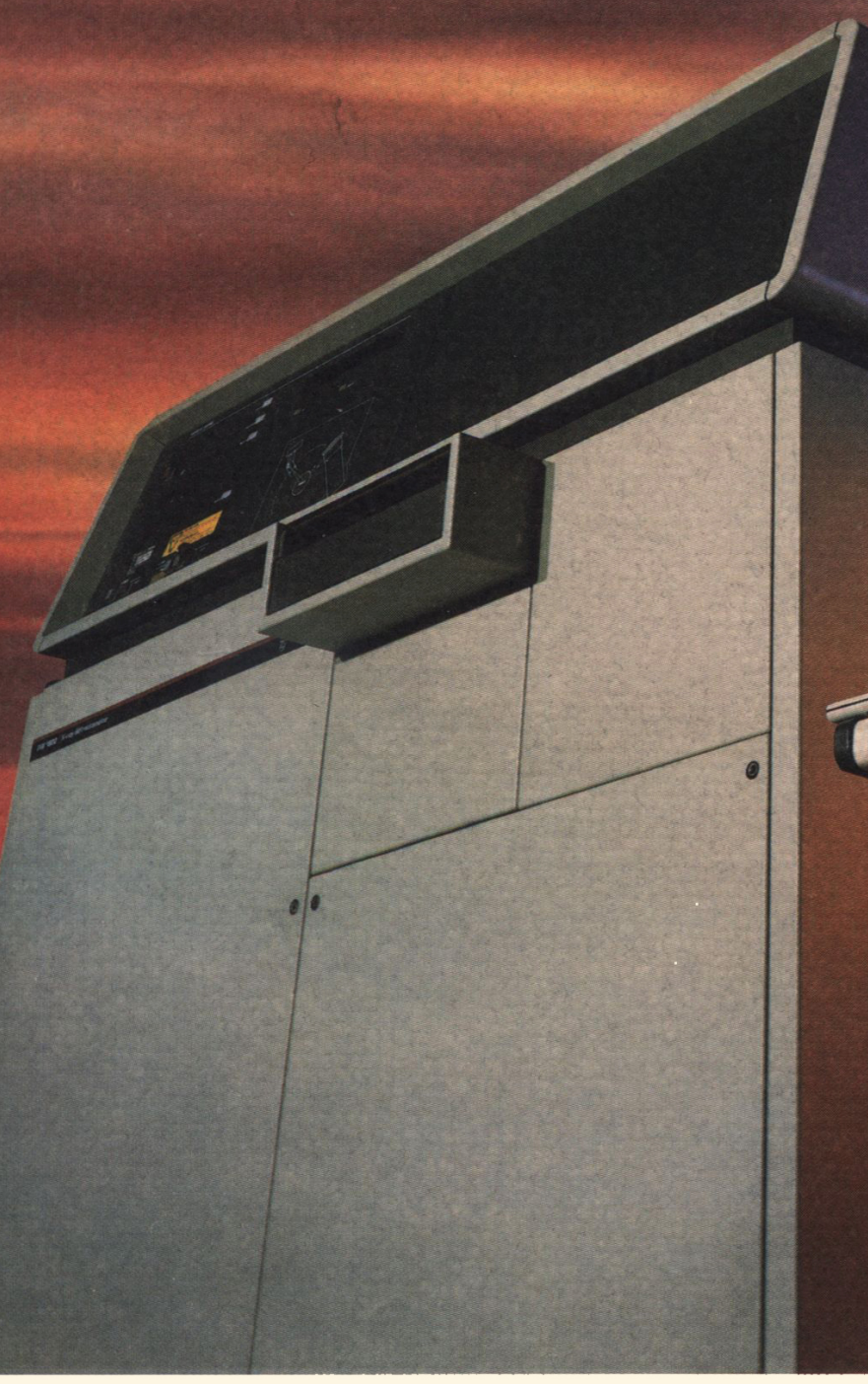

It's the new Philips PW 1800.

It's the most advanced system of its type available anywhere. It's also the most versatile and the easiest to operate.

It's designed for easy, automatic measurement of a wide range of sample types in a variety of forms and quantities including powders, clays, pastes and filters. Built-in electronics control and supervise all diffractometry functions to assure reliability. What's more, the PW1800 actually monitors itself to see that it is functioning properly. And alerts the operator if it senses trouble ahead. In fact, everything about this new system has been engineered to simplify operation.

Even its appearance underscores its uniqueness. It's totally enclosed, totally integrated to assure complete radiation and contamination protection. Which means it can be installed safely and quickly in the laboratory or on the production line.
And among the things you don't see in this unique system is the newly developed, permanently-aligned goniometer that combines ease of operation with high precision and outstanding analytical performance. Built-in robotics for sample handling. And a new, highly-efficient generator that not only requires less space, but actually reduces power consumption as well.

It's the new Philips PW1800. It's the new standard of the industry. And it's backed by the worldwide support resources of the Philips organization.

For complete details, contact:

Philips Electronic Instruments, Analytical X-Ray Group, 85 McKee Drive, Mahwah, NJ 07430, Tel. (201) 529-3800.

(Outside U.S.A.) Philips Scientific \& Analytical Equipment, Industrial \& Electro-acoustic Systems, Lelyweg 1, 7602 EAAlmelo, The Netherlands. Tel (31) 5490-39911.

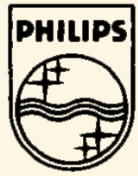

